\title{
Comparing Pedagogical Innovations
}

\author{
Nancy Law, Angela Chow \& Allan H.K. Yuen \\ The University of Hong Kong
}

Keywords: pedagogical innovations, comparative case studies, ICT-supported pedagogy,
comparing innovations

\begin{abstract}
The study of educational innovations has become increasingly important in education research as many countries around the world have embarked on education reforms that aim to change both the goals and practices in education. Studies of models of innovation, evaluations of the impact or outcome of innovations as well as the processes of organizational change are the key approaches taken in this area of research. Understandably, the specific goals and processes involved in each innovation are strongly dependent on the respective institutional, socio-cultural and national contexts and priorities. It is thus not surprising that comparative studies of innovations are relatively rare.
\end{abstract}

SITES M2, as an international comparative study of innovative pedagogical practices involving 28 participating systems, thus faced important methodological challenges the solution of which was no less an innovation in itself. This paper examines the methods of analysis used and the kind of research findings that resulted from the work of three research teams that had conducted comparisons of the case studies of innovation collected, including the work of the SITES M2 International Coordinating Centre (ICC). Even though all three studies attempted to examine similarities and differences across multiple case studies, the analysis conducted by the ICC looked for characterizations of the innovations while the other two studies developed meaningful ways to compare the cases in terms of "levels of innovation” across a number of dimensions. In discussing the methodological differences 
across these studies, this paper pays special attention to how one could compare different innovations in terms of their levels or extents of innovation and what such comparisons may contribute to our learning from technology-supported education innovations. 


\section{Introduction}

The study of educational innovations has attracted increasing attention in education research around the world as many countries have already embarked on education reforms that aim to change both the goals and practices in education. There is also a widespread expectation that such innovations can be leveraged or supported by the use of ICT in the learning and teaching process. However, comparative studies of innovations are relatively rare. SITES M2 (Second Information Technology in Education Study Module 2), as an international comparative study of innovative pedagogical practices using technology involving 28 participating education systems, was the first study conducted under the auspices of the IEA (International Association for the Evaluation of Educational Achievement) that focused on a comparison of pedagogical processes rather than students' learning outcomes ${ }^{1}$. It employed an in-depth qualitative case study approach rather than large scale surveys as have generally been done in other IEA studies. The SITES M2 study thus faced important methodological challenges, particularly in the data analysis stage of the study. The methodological explorations presented in this paper are relevant to comparative studies of pedagogical innovations in general, irrespective of whether technology plays a significant role or not.

While there are many aspects of educational innovations that can be compared, one can broadly categorize them into two levels: pedagogical and institutional. The focus of this paper is to examine comparisons at the pedagogical level and builds on the work of three research teams that had conducted independent analysis on the SITES M2 case reports: the SITES M2 International Coordinating Centre (ICC) (Kozma et al., 2003), the Israel research team led by Mioduser \& Nachimias (Mioduser et al., 2003; Tubin et al., 2003) and the Hong Kong

research team led by $\mathrm{Law}^{2}$ (Law et al., 2003; Law, 2003, 2004). Both the ICC team and the Hong Kong team analyzed cases from the 174 case studies collected internationally while the 
Israeli research team confined their work to the 10 case studies collected in Israel.

This study explores the different methodological approaches that can be used to compare pedagogical innovations using technology through a comparison of different research orientations and methods that have been used by the three research teams in the analysis of the SITES M2 data. In particular, this paper wishes to address four research questions: (1) What were the different approaches that have been used to compare innovations? (2) In what ways can the concept of "levels of innovation” be operationalized? (3) What contribution can a comparison of "innovativeness" make to education and education research? (4) Would there be the methodological differences, if any, between comparisons of pedagogical innovations using Information and Communication Technology (ICT) and comparisons of pedagogical innovations in general?

\section{Differing Research perspectives for studying ICT and pedagogical innovations}

As described earlier, the focus of the SITES M2 was on comparing pedagogical innovations that made significant use of technology. In analyzing the 174 cases collected around the world, the ICC team did not attempt to construct any scale for making comparisons of the levels of innovativeness of the cases. Kozma \& McGhee (2003) focused on providing descriptive accounts of the pedagogical practices through categorizing the practices using cluster analysis and looking at the resulting profiles of features across the clusters. They focused on four main dimensions in building up a characterization of the ICT-based innovations: teacher practices (including methods, roles and collaborations), student practices (including activities and roles), ICT practices (the roles and functions played by ICT in the case studies) and the kinds of ICT used in schools. 
On the other hand, both the Israeli and Hong Kong national research teams were upfront in their desire to examine the cases and to establish some ways to compare them in terms of their innovativeness. Both teams took as their point of departure the assumption that introducing ICT in schools would not per se lead to change and innovation. Instead, the role and impact of ICT use in schools need to be analyzed and understood in the context of broader changes in school education.

The analysis scheme devised by Mioduser et al. (2003) aimed to study systematically transformational processes in schools that extensively embraced the use of ICT. A core assumption underlying the work of this team was that change resulting from technology adoption will develop from a preliminary level of alternations to the school's routine to achieve an initial assimilation of ICT, through a transitional level to finally achieving far-reaching transformations in pedagogical practices and learning processes. They have defined four domains of innovation for their analysis, each of which being one important area of impacts that ICT has created on various aspects of the school milieu.

The Hong Kong SITES research team has a broad range of concerns in their approach to the study of innovative pedagogical practices at the classroom level that encompassed both a desire to capture the characteristics of ICT-using innovative pedagogical practices as well as a comparison of the innovativeness of the case studies. This team also used cluster analysis to build up characterizations of the pedagogical innovations. However, unlike the ICC team, they conducted three separate cluster analysis on the pedagogical characteristics of three distinct dimensions: the curriculum goals, the teachers' roles and the students' roles as they believe the characterizations so constructed will be of greater use to teachers and other educators wanting to learn from the case studies collected in the study. They also constructed 
a fourth characterization, the pedagogical approach employed in the cases, based on the nature of the teaching and learning activities as well as the classroom organizations involved. This aspect of their analysis was reported in Law (2004) and will not be described here. The Hong Kong team also developed and implemented a scheme of analysis to compare the level of innovativeness of the SITES M2 cases collected. They considered the case studies primarily as examples of curriculum innovations that incorporated the use of ICT. Based on their framework for conceptualizing ICT-supported pedagogical practices in school settings (Law et al., 2000), they developed a six dimensional scheme for assessing the levels of innovation for the cases studied: curriculum goals, teachers' roles, students' roles, multiple types of learning outcomes exhibited, connectedness of the classroom with the outside world and the sophistication of the technology used.

It is thus clear from the above description that the three research teams differ not only in the research questions they asked, but also in the perspectives they took in studying ICT-supported pedagogical innovations. In Mioduser et al. (2003)'s analysis, the focus was clearly on the impact of ICT on various aspects of learning and teaching in schools. In the work reported by Law et al. (2003), the focus was on curriculum change and ICT was only one of the various dimensions in their curriculum model. The perspective taken by Kozma \& McGhee (2003) was again different in that out of the four dimensions they identified in their analysis, only two were explicitly linked to the use of technology: the ICT practices employed and the ICT used. The characterizations they identified on other two dimensions, teacher practices and student practices, were focused on features important for pedagogical settings in general, without specific reference to the role of technology. In the rest of this paper, we will focus our discussions on methodologies to compare innovativeness and what differences may be brought about by employing different methods of analysis. 


\section{SITES Criteria for Selection of Innovative Practices}

Before discussing schemes for comparing the pedagogical innovations collected in SITES M2, it is necessary to present the criteria used to select cases for inclusion in the Study. There were four criteria used: (1) there was evidence of significant changes in the roles of teachers and students, the goals of the curriculum, the assessment practices, and/or the educational materials or infrastructure, (2) technology played a substantial role in the practice, (3) there was evidence of measurable positive student outcomes, and (4) the practice was sustainable and transferable. The first of these four criteria is also referred to as the "innovativeness" criterion. While detailed specification and definition of what would be considered as innovative was to be decided by the national selection committees established in each of the participating countries, the design of the study was such that innovation was to be interpreted within the framework of the emergent paradigm as established in the SITES Module 1 Study (Pelgrum \& Anderson, 1999). There, the emergent paradigm was constructed to encapsulate the kind of changes that is generally expected to arise in relation to the nature of schooling and the roles played by teachers, students and parents to meet the new demands on education for life in the information society, in contrast to established practices referred to as the traditionally important paradigm.

Some specific examples for consideration as definitions for innovativeness included:

- $\quad$ students taking responsibility for their own learning, to set learning goals, create learning activities, and/or assess their own and other students’ progress,

- $\quad$ students developing information and media literacy,

- $\quad$ students working collaboratively on complex, extended, real-world-like problems or projects, 
- $\quad$ Breaking down the walls of the classroom by extending the school day, changing the organization of the class, or involving other people in the learning process,

- Breaking down subject boundaries and promoting cross curricular learning,

- $\quad$ Addressing individual differences in learning,

- $\quad$ Providing students with individualized self-accessed learning,

- $\quad$ improving educational equity that may have arisen due to gender, ethnic, social geographic or socioeconomic divides,

- Improve social cohesiveness and understanding by having students interact with groups and cultures that they would not interact with otherwise

\section{Comparing Innovativeness}

\section{Comparing extent of change brought about by the adoption of ICT}

Mioduser et al. (2003) developed a scheme for assessing the levels of innovation for the 10 case studies of ICT-supported innovative pedagogical practices collected in Israel. The scheme comprised nine aspects grouped within four different domains of innovation in a school's milieu: time/space configuration (including the physical space involved, digital space used as well as the constraints posed or otherwise of the time dimension of the curriculum), students' roles, teachers' roles (in relation to students, other teachers and the subject matter content of the study) and the impact of ICT on various aspects of the school curriculum (content, pedagogical organization and assessment) respectively. Mioduser et al. (2003) further defined three levels of innovation to reflect the extents to which the use of ICT triggered a gradual departure from previous patterns of work in each of the nine aspects of the school milieu within the four identified domains of innovation. It was assumed that the process of change brought about by technology adoption would start with a process of assimilation that would involve only minimal changes to existing practices. Transition and 
transformation were labels used to indicate progression towards higher levels of innovation in the use or impact of ICT on each of the nine aspects under study.

Arguably, the most important aspects of pedagogical innovations are those that are expected to contribute directly to education in the information society, that is, the change towards more collaborative and self-directed inquiry-based learning for students, the more facilitative roles for teachers as well as greater connectedness of the classrooms (Pelgrum \& Anderson, 1999, p. 6-7). Therefore, the levels of innovation in the four domains of innovation as defined in Mioduser et al.'s (2003) framework may not contribute equally to levels of "emergence” as described in the SITES study framework. For example, changes occurring in terms of time and spatial configuration may have arisen because of the tyranny of space among learners and teachers, and the extent of transformation possible may also be constrained by the age and level of the students concerned, or simply by the level of technology access available. Further, the students' role in as defined in Mioduser et al.'s (2003) framework focused on the levels of innovation in terms of students' roles in using ICT only and may not reflect the students' main roles in the pedagogical practice overall. Therefore, cases with high scores and are thus more "transformative” according to this analysis scheme may not necessarily be pedagogically more exciting or "emergent” than cases with a low score in this domain. Furthermore, there is no necessary correlation between the levels of change for the different domains.

Using the framework that Mioduser et al. (2003) developed, Tubin et al. (2003) reported on their analysis of the 10 Israel cases of innovative case studies collected in SITES M2. They found that in most schools, the extent of change was not the same for the different aspects of change analyzed. A mean overall "level of innovation” was also computed for each school across all the 9 aspects and the analysis found large variations in score from 2.0 to 4.7. While 
this mean overall "level of innovation” may not be easily interpretable since it is an aggregate score from rather different domains, the findings also indicated that a high level of transformation may not be found in all domains even for cases selected as examples of innovative practice. Another noteworthy finding was that the levels of innovation in the various domains were highly correlated, with the exception of teacher's role with other teachers, indicating that changes in teachers' communication and work patterns in the 10 Israeli innovative case studies had little effect on changes in the other aspects. The analysis also showed that didactic solutions was the domain with the highest correlation with nearly all other domains, indicating that this was the central domain of innovation for the 10 cases studied out of the four domains identified.

Other than computing the mean overall "level of innovation" for each school as was done by Tubin et al. (2003), it would in fact be interesting to compare the mean extent of change across the 9 aspects based on the mean score for each aspect for the 10 cases studied. A calculation based on the scores provided by Tubin et al. (2003) revealed that the least change was recorded in the area of physical space (2.6) and the highest in curriculum content (3.8), while the overall mean across all domains and cases was 3.3.

The findings from this study revealed some important patterns emerging from a cross-case comparison of levels of innovation. However, it is not clear whether the patterns so detected would be replicated in the other 164 cases collected in SITES M2, and whether there would be national/regional differences in these patterns. This would be a worthwhile follow-up study to conduct. 
The Hong Kong SITES National Research Team also developed a framework for differentiating the case studies in terms of levels of innovation along several dimensions (Law et al., 2003). However, as described in the earlier section, this team considered the case studies collected as examples of curriculum innovation that has incorporated the use of ICT. For this team, the concept of emergent pedagogical practices was grounded on the belief that innovations need to build on existing practices for it to be viable and yet need to have the courage to break new grounds in order to be fruitful. Each case study was examined to look for indicators of change (as in breaking new ground) on a continuum along a traditional versus emergent dichotomy for key dimensions of analysis. The following excerpt from their online research report ${ }^{2}$ provides a clear encapsulation of their standpoint:

\section{"ICT and Educational Innovations}

The introduction of ICT into the school curriculum began around the early 1980s. With the short time span of a quarter century, not only has the presence of ICT in schools increased exponentially in many countries, the key justification for their presence (Why should ICT be introduced into the curriculum?) has also changed. The technological changes brought about by ICT have lead to deep changes in the workplace. Towards the end of the 20th century, many countries have identified the development of 21st century competencies through educational reforms that encompass fundamental changes in pedagogy that integrate the use of ICT to be their top educational priority. The Second International Information Technology in Education Study (SITES M2) has thus identified innovative pedagogical practices the focus of this comparative study in order that we can learn from the most innovative cases of ICT use in schools around the world how ICT can transform our classrooms to better prepare our students for the future. The Hong Kong SITES research team has analyzed the SITES cases collected from around the world based on an analysis model that conceptualizes ICT use as an integral part of curriculum interactions within the context of school, regional and national policies and strategies.”

Six dimensions were identified by the team to be the most important aspects of any curriculum implementation using ICT that warrants detailed examination (Law, 2003; Law et al., 2003): 
- Intended curriculum goals of the innovative practices

- Pedagogical role(s) of the teachers

- $\quad$ Role(s) of the students

- $\quad$ Nature and sophistication of the ICT used

- Multidimensional learning outcomes exhibited

- Connectedness of the classroom

To conduct cross-case comparisons of innovation, scales of innovativeness were developed to reflect the magnitude of change along each of the 6 dimensions of analysis, taking the "traditional" classroom to be typically one that is isolated, knowledge-focused, teacher-centered, does not use ICT and only assesses students on cognitive learning outcomes. A 7-point Likert Scale was used to score each of the case using the scoring rubric published at http://sitesdatabase.cite.hku.hk/i_classroom/P_3_1.htm, with 1 point given to practices at the most traditional end of the scale, 4 points given to those at the mid-point of the scale and demonstrating emergence while 7 points were given to practices at the most innovative end of the scale. Therefore, six innovation scores were assigned to each case based on the specific pedagogical situations described in the case report on the six identified dimensions: the curriculum goal score (G_score), the teacher's role score ( $T$ _score), students' role score (S_score), ICT sophistication score (ICT_score), multidimensional learning outcome score (M_score) and connectedness score (C_score).

Law et al. (2003) reported large diversities along each of these 6 dimensions when the case studies were examined. While some of the features observed were very similar to traditional practices, others had rather innovative features that were rarely found in present day classrooms. The research team did not see it appropriate to compute an aggregate innovation 
score for each case out of the 6 innovation scores, but developed a graphical representation to provide a bird's eye view of the team's rating for the extent of innovativeness of each case along the 6 dimensions based on the case report descriptions. As can be seen from Figure 1, the innovation profile for different cases analyzed may be rather different.

(Insert Figure 1 about here)

This team used their analysis framework to analyze not only the case studies collected in Hong Kong, but also those collected internationally. In analyzing the case reports, they found great variation in the level of details available about the practices in the collection of reports. In particular, some of the case reports contain very general descriptions of teachers' and students' activities that did not make reference to specific curriculum or learning contexts. This may be related to the fact that some countries participated in both the SITES M2 and the OECD (Organization for Economic Co-Operation and Development) studies and used the same set of case studies for both studies. The case selection criteria for these two studies were different and the OECD case studies focused on school-wide innovations. In the end, the team considered 83 reports to have sufficient details for the purpose of scoring the levels of innovation for the classroom level analysis.

The team found from their analysis that there were large diversities across cases. The profiles they obtained from the analysis indicated that cases rated as highly innovative in all six dimensions were rather rare, while many were highly innovative in one or a few of the 
dimensions. This probably indicates that in experimenting with novel ways of organizing teaching and learning, the change agents in the different practices did not give the same priority to the six dimensions. Based on the innovation scores assigned to the 83 cases, some interesting observations can be found from an exploration of the means and standard deviations of the innovation scores along the six dimensions.

(Insert Table 1 about here)

It is interesting to note from Table 1 that out of the six dimensions of innovation, ICT sophistication was the dimension that achieved the highest mean innovation score as well as the smallest standard deviation. This indicates that while the overall ICT availability differs greatly in different countries around the world (Pelgrum \& Anderson, 1999), the cases selected as innovative by the different countries were much more similar in terms of the technology used than any of the other dimensions. Furthermore, the connectedness of the classrooms had the largest standard deviation, indicating that connectedness was possibly more dependent on other factors such as the prevalent classroom culture than hardware/software availability and connectivity.

\section{Exploring Regional Differences in Technology-supported Pedagogical Innovations}

While the innovation scores cannot convey the complexities and richness encapsulated in each of the 5000-word case study reports, they provide a framework and crude measures for making a variety of comparisons, including cross-national or regional ones, the results of 
which can be used as leads for further explorations. Table 2 gives a breakdown of the innovation scores for the cases found in different geographic regions. It reveals sizeable regional differences in terms of the profiles of innovation. In particular, it is noteworthy that of all the 6 dimensions, the multidimensional learning outcome score had the lowest mean score for nearly all the regions and had a score below " 4 " for all regions except Western Europe, indicating that change along this dimension had not reached the "emergent” level, or the mid-point of the innovation scale. Furthermore, the regional statistics reveal that Western Europe had the highest mean innovation score for all dimensions, except for the dimension ICT sophistication. On the other hand, with the exception of the ICT sophistication dimension, the mean innovation scores for Asia were below 4 for all the other 5 dimensions.

(Insert Table 2 about here)

By virtue of their selection by nationally established committees for participation in the SITES M2 study, the cases analyzed were outstanding exemplars rather than "representative" of the educational practices generally found in schools in their respective national contexts. However, as social institutions, the socio-cultural/curriculum contexts and pedagogical practices found in even the most innovative schools cannot be entirely divorced from the mainstream practice generally prevalent in schools in the same national context. The regional differences in innovation profile described above can thus be interpreted as an indication that the definition of emergence in the SITES study was most closely aligned to the predominant pedagogical practice characteristics found in schools in Western Europe and furthest from those found in Asian schools generally. 
The six innovation scores assigned to each case reflected the level of innovativeness based on the features related to six distinct pedagogical dimensions, which are nonetheless also interrelated. An examination of the correlation of the different innovation scores in Table 3 revealed important observations. The ICT sophistication score has the lowest correlation with all the other innovation scores. Furthermore, the correlation coefficients of the ICT sophistication score were significant only for those with the teacher's role scores and the classroom connectedness scores. On the other hand, the teachers' role scores was the only dimension that showed significant and mostly very high correlation coefficients with all the other five dimensions, indicating that teachers' roles had the strongest influence on the overall level of innovation for the cases analyzed.

(Insert Table 3 about here)

Examinations of the correlation between the different innovation scores across the different geographical regions revealed rather prominent differences. Results presented in Tables 4 and 5 show that for the cases collected in Western Europe and America, the two regions that had the longest history of infusing ICT into the curriculum, the ICT_scores were positively correlated only with the connectedness score. However, these results were not replicated in the corresponding figures for cases collected in Eastern Europe or Asian (see Tables 6 and 7), the two regions with a relatively short history of ICT integration across the school curriculum. For cases collected in these two regions, the ICT sophistication score correlated much more 
strongly (and positively) with the other dimensions, except for the multidimensional learning outcomes dimension.

(Insert Table 4 - 7 about here)

These correlation patterns are indeed very intriguing and needs further exploration. It is apparent from these results that in Asian and East European countries, the teachers involved in practices using sophisticated technology also tended to be more willing to experiment with more innovative, less traditional pedagogies. On the other hand, in Western Europe and America where teachers had been exposed to and had longer experience of using technology in their own teaching, the level of sophistication of the technology used in the innovative practices collected appeared to have no significant or positive relationship with the level of innovativeness in the other dimensions. Venezky \& Davies (2002) concluded from their study of ICT-supported education innovation collected in the OECD countries that ICT is only a lever for change, and not a catalyst, meaning that the presence of ICT per se would not lead to the emergence of innovation. Instead, ICT could be used to leverage educational innovations to bring about more effective transformation. The regional correlation statistics listed in Tables 4-7 indicate that the impact of ICT on education innovation is possibly much more complex and is likely to differ for systems where schools have different levels of general access to ICT. What does the above results tell us about the impact of technology on pedagogical practices, especially in relation to the much referred to changes such as the changed roles of learners and teachers as well as changed goals of education for the information age? Do the regional differences reveal a necessary pathway of change in schools 
as technology become more commonplace in schools?

\section{Conclusion}

The SITES M2 study posed serious methodological challenges for researchers in the field of international comparative studies of education. The challenges involved are two-fold. First of all, comparative studies involving complex multiple case studies of the scale found in the SITES M2 study are very rare. Another major challenge relates to the lack of established methodologies for the international comparative study of educational innovations. Studies of educational innovations were generally done at individual institutional levels, or across several institutions that share some similarities, in terms of contexts or the nature of innovation implemented. SITES M2 thus posed serious challenges in terms of both the scale and complexity involved. The published findings for SITES M2 are still very limited compared to the richness and massiveness of the data that have been collected. Nevertheless, they do provide important insight to our understanding of ICT-supported pedagogical innovations. This paper attempts to provide a discussion of some of the methodological issues revealed through the published findings related to this study. In particular, this paper presented two approaches to assessing the level of innovation, both of which contributed important insights to the understanding of the nature and complexity of changes found in ICT-supported pedagogical innovations selected around the world. 


\section{References}

Kozma, R. (Ed.). (2003). Technology, Innovation, and Educational Change: A Global Perspective. Eugene, OR: ISTE.

Kozma, R., \& McGhee, R. (2003). ICT and Innovative Classroom Practices. In R. Kozma, J. Voogt, W. Pelgrum, R. Owston, R. McGhee, R. Jones, R. Anderson (Ed.), Technology, Innovation, and Educational Change: A Global Perspective. Eugene, OR: ISTE.

Law, N., Yuen, H.K.,Ki, W.W., Li, S.C., Lee, Y. \& Chow, Y. (Ed.). (2000). Changing Classrooms and Changing Schools: a study of good practices in using ICT in Hong Kong Schools. Hong Kong: CITE, University of Hong Kong. Retrieved from http://sitesdatabase.cite.hku.hk/online/index.asp.

Law, N. (2003). Innovative Classroom Practices and the Teacher of the Future. In C. Dowling \& K. W. Lai (Eds.), Information and Communication Technology and the Teacher of the Future (pp. 171-182). Dordrecht: Kluwer Academic Publishers.

Law, N. (2004). Teachers and Teaching Innovations in a Connected World. In A. Brown \& N. Davis (Eds.), Digital Technology, Communities and Education. London: Kogan Page.

Law, N., Yuen, H.K., \& Chow, A. (2003). Pedagogical Innovations and Use of ICT. Paper presented at the 10th Biennial Conference of the European Association for Research on Learning and Instruction, August 26-30, 2003, Padova, Italy.

Law, N., Yuen, H. K., Chow, A., \& Lee, Y. (2003). A comparative study of "Innovative Pedagogical Practices Using Technology": a secondary analysis by the Hong Kong Study Centre. Hong Kong: Centre for Information Technology in Education, University of Hong Kong. Accessible from http://sitesdatabase.cite.hku.hk/online/index.asp.

Mioduser, D., Nachimias, R., Tubin, D., \& Forkosh-Baruch, A. (2003). Analysis Schema for the Study of Domains and Levels of Pedagogical Innovation in Schools Using ICT. Education and Information Technologies, 8(1), 23-36. 
Pelgrum, H., \& Anderson, R. (Ed.). (1999). ICT and the Emerging Paradigm for Life Long Learning. Amsterdam: IEA.

Tubin, D., Mioduser, D., Nachimias, R., \& Forkosh-Baruch, A. (2003). Domains and Levels of Pedagogical Innovation in Schools Using ICT: Ten Innovative Schools in Israel. Education and Information Technologies, 8(2), 127-145.

Venezky, R. L., \& Davis, C. (2002). Quo Vademus? The Transformation of Schooling in a Networked World. Paris: OECD/CERI. 
Methodological Approaches to Comparing Pedagogical Innovations Using Technology

Footnotes

1. Details about the conceptual framework and design of the SITES M2 study can be found at http://sitesm2.org/mod2.html

2. More details of the research findings can be found from their website, http://sitesdatabase.cite.hku.hk/online/index.asp

3. http://sitesdatabase.cite.hku.hk/ict_innovation/main.asp?in_page=3

4. The 4 Australian cases included in this analysis were categorized together with cases from West Europe. 
Figure 1. A diagrammatic representation of the extent of innovativeness for two of the case studies collected in Hong Kong.
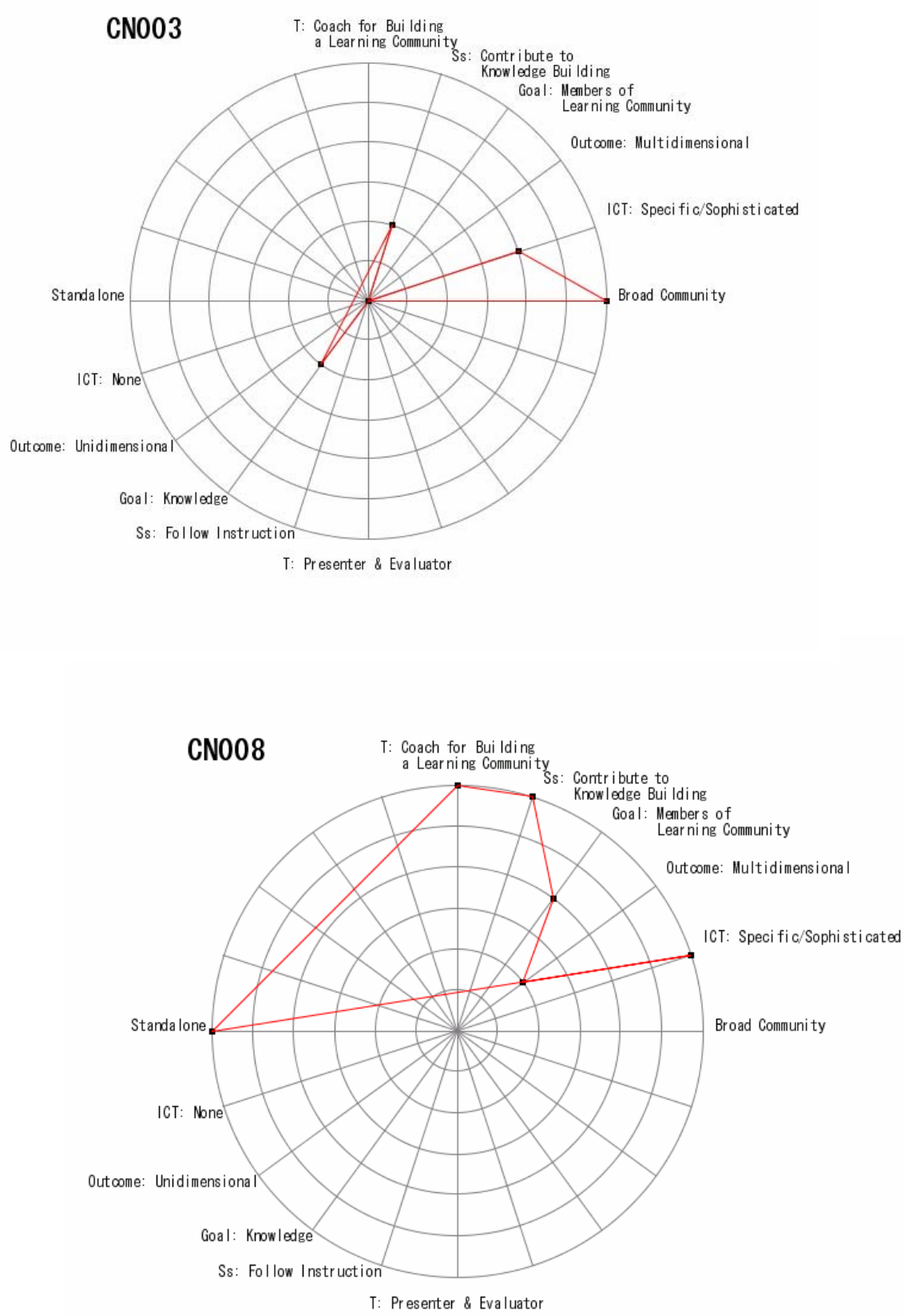
Table 1. The mean innovation score and related descriptive statistics along each of the six dimensions of innovation for the 83 cases analyzed by Law et al. (2003).

\begin{tabular}{lcccc}
\hline \multicolumn{1}{c}{ Dimension of innovation } & $\begin{array}{c}\text { Mean innovation } \\
\text { score }\end{array}$ & Min. score & Max. score & $\begin{array}{c}\text { Std. } \\
\text { Deviation }\end{array}$ \\
\hline Curriculum goals & 4.18 & 1 & 6 & 1.30 \\
Teacher's roles & 4.34 & 2 & 7 & 1.35 \\
Students' roles & 4.31 & 2 & 7 & 1.61 \\
ICT sophistication & 5.71 & 5 & 7 & 0.74 \\
Multidimensional learning outcomes & 4.13 & 1 & 7 & 1.66 \\
Connectedness of the classroom & 4.16 & 1 & 7 & 2.06 \\
\hline
\end{tabular}


Table 2. The mean innovation score and related descriptive statistics along each of the six dimensions of innovation for the 81 cases analyzed by Law et al. (2003) as distributed across geographical regions ${ }^{4}$.

\begin{tabular}{lcccc}
\hline \multicolumn{1}{c}{ Dimension of innovation } & $\begin{array}{c}\text { Western } \\
\text { Europe }(45) *\end{array}$ & $\begin{array}{c}\text { America } \\
(8)\end{array}$ & $\begin{array}{c}\text { East Europe } \\
(6)\end{array}$ & $\begin{array}{c}\text { Asia } \\
(25)\end{array}$ \\
\hline Curriculum goals & 4.60 & 4.25 & 3.67 & 3.48 \\
Teacher's roles & 4.74 & 4.13 & 4.00 & 3.64 \\
$\begin{array}{l}\text { Students' roles } \\
\text { ICT sophistication }\end{array}$ & 4.57 & 4.13 & 4.50 & 3.76 \\
$\begin{array}{l}\text { Multidimensional learning } \\
\text { outcomes }\end{array}$ & 5.79 & 6.00 & 5.50 & 5.52 \\
Connectedness of the classroom & 4.45 & 3.88 & 3.33 & 3.76 \\
\hline
\end{tabular}

* The figures in brackets are the number of case studies from countries within the respective region that were included in this analysis. 
Table 3. Correlation matrix of the dimension scores of cases across all regions $(\mathrm{N}=83)$

\begin{tabular}{|c|c|c|c|c|c|c|}
\hline & G_score & T_score & S_score & ICT_score & M_score & C_score \\
\hline G_score & 1 & & & & & \\
\hline T_score & $.74^{* *}$ & 1 & & & & \\
\hline S_score & $.67 * *$ & $.77 * *$ & 1 & & & \\
\hline ICT_score & 0.14 & $.22 *$ & 0.06 & 1 & & \\
\hline M_score & $.56^{* *}$ & $.59 * *$ & $.72 * *$ & 0.07 & 1 & \\
\hline C_score & 0.21 & $.31 * *$ & $.26 *$ & $.31 * *$ & $.28 * *$ & 1 \\
\hline
\end{tabular}

${ }^{*} \mathrm{p}<0.05,{ }^{* *} \mathrm{p}<0.01$ 
Table 4. Correlation matrix of the dimension scores of cases within Western Europe $(\mathrm{N}=42)$

\begin{tabular}{lllllll}
\hline & G_score & T_score & S_score & ICT_score & M_score & C_score \\
\hline G_score & 1.00 & & & & \\
T_score & $0.64^{* *}$ & 1.00 & & & \\
S_score & $0.56^{* *}$ & $0.67^{* *}$ & 1.00 & & \\
ICT_score & -0.08 & -0.01 & -0.02 & 1.00 & \\
M_score & $0.50^{* *}$ & $0.57^{* *}$ & $0.81^{* *}$ & 0.17 & 1.00 & \\
C_score & 0.04 & 0.15 & 0.17 & $0.42^{* *}$ & 0.20 & 1.00 \\
\hline & $* * \mathrm{p}<0.01$ & & & & &
\end{tabular}


Table 5. Correlation matrix of the dimension scores of cases within America ( $\mathrm{N}=8)$

\begin{tabular}{lllllll}
\hline & G_score & T_score & S_score & ICT_score & M_score & C_score \\
\hline G_score & 1.00 & & & & \\
T_score & 0.12 & 1.00 & & & \\
S_score & 0.60 & $0.79 *$ & 1.00 & & \\
ICT_score & -0.52 & 0.00 & -0.43 & 1.00 & & \\
M_score & 0.14 & 0.21 & 0.49 & -0.21 & 1.00 & \\
C_score & -0.31 & 0.17 & -0.13 & 0.52 & -0.36 & 1.00 \\
\hline & $* \mathrm{p}<0.05$ & & & & &
\end{tabular}


Table 6. Correlation matrix of the dimension scores of cases within Eastern Europe ( $\mathrm{N}=6)$

\begin{tabular}{lllllll}
\hline & G_score & T_score & S_score & ICT_score & M_score & C_score \\
\hline G_score & 1.00 & & & & & \\
T_score & $0.93^{* *}$ & 1.00 & & & & \\
S_score & $0.84^{*}$ & 0.72 & 1.00 & & & \\
ICT_score & 0.30 & 0.52 & 0.40 & 1.00 & & \\
M_score & 0.72 & 0.48 & 0.66 & -0.21 & 1.00 & \\
C_score & 0.39 & 0.27 & 0.62 & 0.17 & 0.71 & 1.00 \\
\hline & $* \mathrm{p}<0.05, * * \mathrm{p}<0.01$ & & & &
\end{tabular}


Table 7. Correlation matrix of the dimension scores of cases within Asia ( $\mathrm{N}=25)$

\begin{tabular}{lllllll}
\hline & G_score & T_score & S_score & ICT_score & M_score & C_score \\
\hline G_score & 1.00 & & & & \\
T_score & $0.78^{* *}$ & 1.00 & & & \\
S_score & $0.76^{* *}$ & $0.85^{* *}$ & 1.00 & & \\
ICT_score & 0.35 & $0.45^{*}$ & 0.28 & 1.00 & \\
M_score & $0.58^{* *}$ & $0.64^{* *}$ & $0.69 * *$ & -0.10 & 1.00 & \\
C_score & 0.17 & 0.30 & 0.28 & -0.03 & 0.35 & 1.00 \\
\hline
\end{tabular}

